\title{
A Ferroelectric Transition in Proton Ordered Ice Crystallised in Liquid Nitrogen released Laser Light, Explaining the Origin of Life with many Consequences
}

\section{Michael Thomas Deans*}

Freelance, 4 Cavendish House, Cavendish Road, Chiswick, London, W4 3TD, UK

\begin{abstract}
A serendipitous observation during a student class practical with liquid nitrogen led me to propose that a variant of cubic ice crystallizing on the silica helium thermometer bulb had distorted it. Pauling argued the $\mathrm{H}$-bonds in hexagonal ice retain entropy at $0 \mathrm{~K}$. Recent evidence for a ferroelectric transition in 'ice XIc' at $\sim 72 \mathrm{~K}$ validates that suggestion.
\end{abstract} This paper introduces a lifetime's research based on three axioms:

1. Proton ordered ice crystallized in liquid nitrogen undergoes a ferroelectric transition at $\sim 72 \mathrm{~K}$ releasing latent energy as $\sim 4 \mu$ laser light, 'ice light', matching phosphodiester bond energy.

2. Ice crystallizing in liquid nitrogen on Earth's poles during a primordial ice age released ice light. Polarised by multiple reflection in ice clouds and surface ice, it photo-phosphorylated nucleotides in tropical waters, creating a 'noodle soup' of chiral DNA. Some formed 'transport DNA's, tDNAs, tRNA analogues.

3. tDNAs used an ice light powered mechanism to actively transported substrates into Oparin's 'coacervate' proto-cells.

The resulting model for the origin of life makes predictions consistent with scientific research. Applying evolutionary and thermodynamic principles reveals life's atomic alphabet, molecular vocabulary and metabolic grammar, predating protein synthesis evolving. It offers new perspectives on metabolism, bioenergetics, genetics, endocrinology and tissue differentiation:

- Dietary prevention of health disorders including: heart attacks, cancers, diabetes and Alzheimer's disease.

- Energy coupling for $\mathrm{N}$-fixation and power generation.

- Medical diagnosis pre-empting pharmaceutical interventions.

'Minions', DNA-protein complexes evolved to pack chromosomes and facilitate their replication, are bound by proton ordered $\mathrm{H}$-bonds using a 63-character alphabet to store information as 18-letter words. Similar words resonate and nerve fibres act as wave guides, explaining brain function. Trace element supplements and Al modelled on 'minions' could improve health and create user-friendly IT. These proposals are consistent with science, philosophy and tradition.

\section{Ice as Ordering Force}

Water molecules' irregular shape explains the sixteen known phases of ice [1]. Ice Ic shares diamond's cubic structure, (Figure 1A), at liquid nitrogen temperature. Water molecules are usually randomly oriented, accounting for Linus Pauling's residual entropy. They tend to align below the observed ferroelectric transition temperature, $\sim 72$ $\mathrm{K}$ [2]. Re-crystallisation in liquid nitrogen yields an orderly variant of cubic ice. Its ferroelectric phase transition is accompanied by shape change, (Figure 1B), releasing 'ice light', explaining this anomaly.The estimated wavelength of ice light, $\lambda$, is $\sim 4 \mu$. Reflection in ordinary ice, (Figure 2A) polarises it. Planetary temperatures observed by astronomers [3] are consistent with polar liquid nitrogen and Charles Darwin's warm equatorial waters coexisting during a primordial ice age. Over millions of years, dynamic equilibrium maintained small nucleotide concentrations. Diurnal, annual and random temperature fluctuations caused ice light release, creating DNA, it's more stable than RNA.'Transport DNA's, analogues of transfer RNA involved in modern protein synthesis, lined pores through Oparin's 'coacervate' membranes [4] with $\mathrm{H}$-bonds, (Figure 2B). Electric storms polarized the $\mathrm{H}$-bonds, creating a membrane potential. When ice light depolarized them, the residual electric field ingested charged complexes, (Figure 2C). This explains how order arising in ice created life from chaos.

\section{The Bioenergetics of Proton Ordered H-bonds}

In isolation, $\mathrm{H}$-bonds are weak and disorderly,en masse they're strong. All biological systems use photochemistry, $1 / 2$-wave resonant cavities for ice light couple chemical to mechanical energy, they're more efficient than processes subject to thermodynamic constraints:

- Adrian Huxley's model for striated muscle contraction [6], involving the random attachment of actin to myosin is as inefficient as a steam engine. Hydrolysis of ATP releases ice light and sarcomeres change shape, forming $1 / 2 \lambda$ cavities resonating with it, sharing the efficiency of electric motors.

- Peter Mitchell presumed unit membranes were semi-permeable when he proposed chemiosmosis [7]. $\mathrm{Na}^{+} / \mathrm{K}^{+}$exchange maintains membrane potential, see Sensitivity. It creates an electric field preventing charged ions or polarisable molecules

*Corresponding author: Michael Thomas Deans, Freelance, 4 Cavendish House Cavendish Road, Chiswick, London, W4 3TD, UK, Tel: 02089956525; E-mail: michaeltdeans@gmail.com

Received March 25, 2015; Accepted May 22, 2015; Published May 31, 2015

Citation: Deans MT (2015) A Ferroelectric Transition in Proton Ordered Ice Crystallised in Liquid Nitrogen released Laser Light, Explaining the Origin of Life with many Consequences. Med chem 5: 211-216. doi:10.4172/2161-0444.1000266

Copyright: ( 2015 Deans MT. This is an open-access article distributed under the terms of the Creative Commons Attribution License, which permits unrestricted use, distribution, and reproduction in any medium, provided the original author and source are credited. 


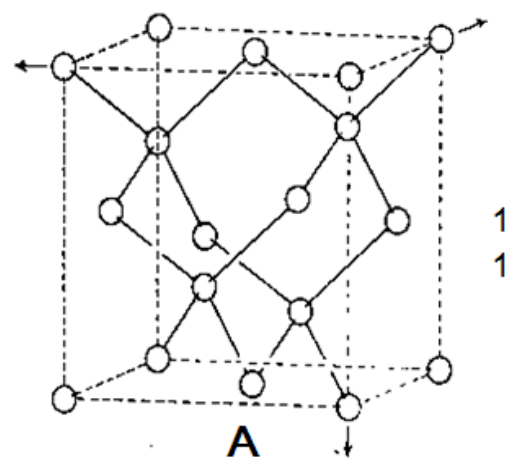

130K Hexagonal/cubic $110 \mathrm{~K}$ Cubic/vitreous 77K Nitrogen boils 72K Ferroelectric

\section{B}
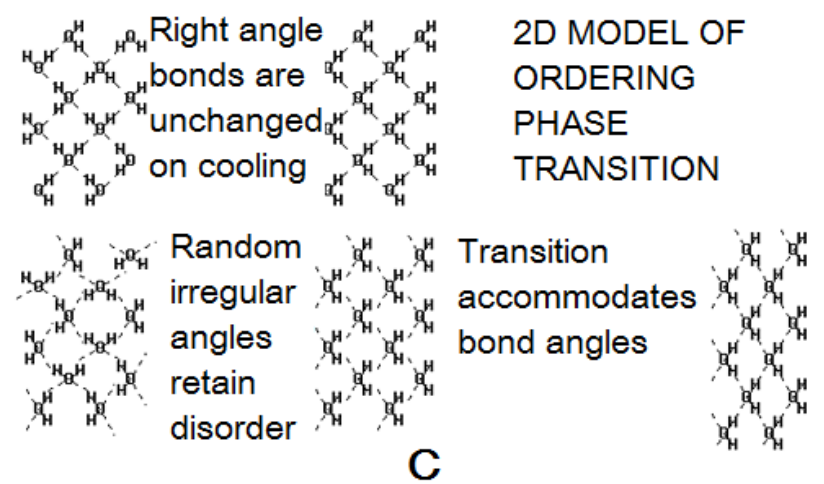

Figure 1: A. Diamond structure, B. Ice transition temperatures, C. Twodimensional model of ferroelectric phase transition.

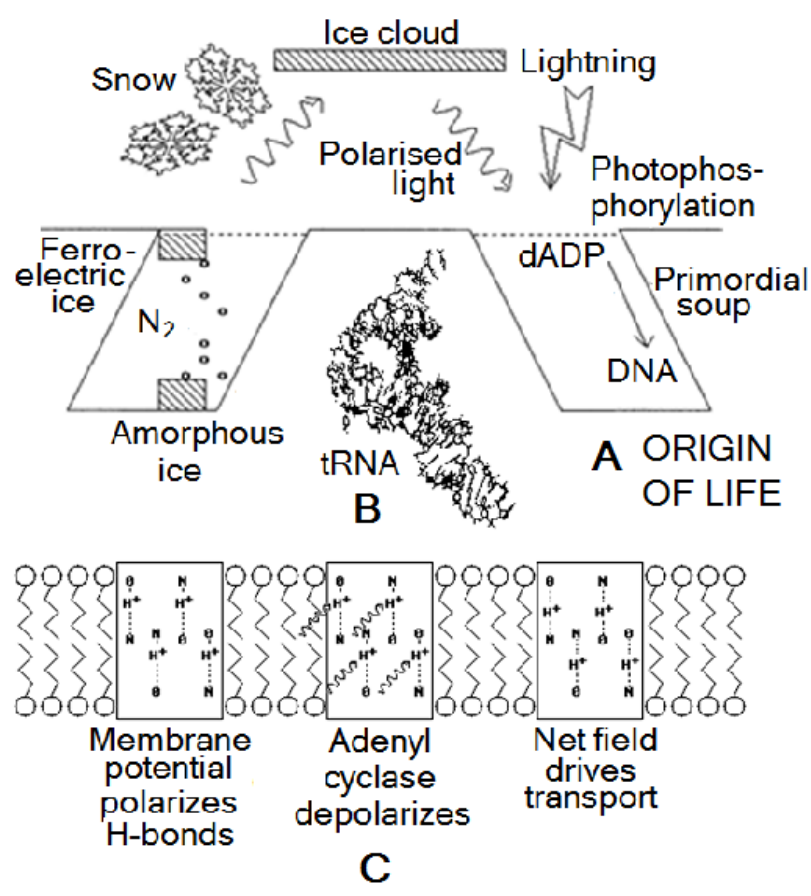

Figure 2: A. Origin of life, B. tRNA $\mathrm{Phe}_{\text {[ }}$ [5], C. Active transport ratchet mechanism.

such as water from diffusing, see Osmoregulation. 'Proton gradients' and osmotic pressure are meaningless at molecular scales. Mitochondria are commensurate with $\lambda$, accommodating ice light and coupling oxidative phosphorylation to kinase enzymss, feedback-inhibiting ATPase.
- Nicocotinamide on NAD and NADP exchanging protons fixes nitrogen more efficiently than the Haber process. Parallel reactions account for proton transport and release of atmospheric oxygen, see Respiration.

- The consensus model for active transport, involving barrels of $\alpha$-helices opening and closing, is less efficient than DNA's ratchet mechanism, (Figure $2 \mathrm{C}$ ).

- Centrioles are $\sim 1 / 3 \lambda$ long, resonating with ATP's phosphodiester energy which accumulates in their nine peripheral rods. They simultaneously feed energy along spindle proteins. These comprise three $\alpha$-helical proteins forming helices, each incorporates three paths of alternate conjugated double bonds transmiting ice light to centromeres.

- Chromosomes at cell division have circumference $\sim 1 / 2 \lambda$, oscillating $\mathrm{H}$-bonds between their amino acid $\omega$-amines and phosphate groups accelerate protons along spiral 'minion' tunnels. They create alternating magnetic fields with frequencies dependent on chromosome length. The chromosomes repel one another, causing them to separate, if the centrioles converged they'd disobey Isaac Newton's third law of motion.

- The cavities in photosynthetic grana are smaller, accommodating visible wavelengths. Exchange of light quanta between cytochrome pairs releases ice light, replacing the consensus view of cytochromes forming electron chains. Electric currents would short-circuit in the wet biological environment.

- Retinal rods and cones encode colour and other features on minions, sending signals to the brain for recognition. Minion logic bypasses the pixel image processing computers use.

- Ear cells lining the cochlea encode sounds' pitch, frequency and timbre, similarly putting recognition before analysis.

\section{Origin of Life}

Precipitation in polar pools of nitrogen during a primordial ice age created ice XIc. Its ferroelectric phase transition converted random temperature fluctuations to ice light. Multiple reflection by surface ice and ice in clouds polarized it. On reaching Charles Darwin's warm tropical waters it photophosphorylated nucleotides. The primordial soup became a 'noodle soup' of chiral DNA. Some formed tDNAs which actively transported substrates, including nucleotides, to Oparin's 'coacervate' proto-cells. A tDNA replica and the cell bursting in two created daughter cells, life had started. Mutant tDNAs selected various nutrients. Eventually, a family of 64 types evolved, each with a matching substrate-carrier complex consisting mostly of trace element ions (Figure 4A) shows some of the nine substrate-carrier complexes underlying the metabolic pathways summarised under Trace element nutrition. tDNA replication constituted the start of life.All life forms share a common atomic alphabet and molecular vocabulary. Micronutrient deficient diets arising as human civilizations evolve are problematic. Cataloguing medical, veterinary and pharmaceutical data, tradition, philosophy and belief systems reveals nine mutually independent biochemical pathways. Each is associated with a different nutrient requirement, chemistry and pathology. Together, they offer a comprehensive guide for diagnosing, preventing and treating most common maladies. Biotechnologists breaching life's early established principles may imperil its survival.

\section{Minion Structure and Function}

'Minion' connotesmindandsubservience. Every humancell nucleus 
contains 1.8 Mminions. They incorporate 1,701 DNA base pairs held flat by anti-parallel $\beta$-pleated protein sheets, (Figure $3 \mathrm{~A}$ ). The uncoiled DNA retains the base-pair spacing and overlap found in the B-helix. The proteins have alternate neutral Ala | Leu | Ile | Val and basic Arg | Lys amino acids, Pro makes an asymmetric U-bend. Gramicidin S, (Figure 3B), has an analogous structureTwenty-one nine-base-pair units form a coil and nine coils bound by similar proteins complete a minion. Super-coiled minions pack chromosomes neatly for efficient, error-free replication mediated by proton currents around their $\sim \frac{1}{2} \lambda$ circumference. 'Nucleosome core particles' are preparative artefacts. Ala, Leu, Ile and Val bind specifically to bases Cytosine, Guanine, Adenine and Thymine, mnemonic ALIVe CiGAreTte, preserving DNA sequence integrity, (Figure 3C).

\section{The Chip in the Brain}

To address Turing's question Can machines think, computers need do better than answer 'Yes' or 'No'. I deduced the structure of 'minions', the chips in our brains, by iteration. Minions 'think' both laterally and vertically. One of the H-bonds connecting basic Arg | Lys amino acid $\omega$-amines to DNA phosphates on the inner and outer surface of each coil is reversed. They form $18^{\star} 63$ proton-ordered H-bond arrays storing information as eighteen-letter words using a sixty-three character alphabet. Those in any cell nucleus could remember the Bible and Shakespeare. Memory recall involves resonance between minions storing similar words, nerve fibres serve asoptic fibres, theirsynaptic junctions as filters. Minions have evolved, taking natural intelligence beyond computer technology. They use exponents and logarithms to make comparisons, consistent with using ratios and percentages (mixing metaphors in politics an journalism can be confusing). Their 18 frequency bands embrace theelectromagneticspectrum, equivalent to a piano spanning 103 octaves. Each has an associated quality, personality type, sense, etc, Table 1 . Theneural network brain model fails to account for this.Each word playsacoloured, personality dependent chord, partial resonance achieves compromise. Lateral thinking is equivalent to transposing between musical key, questions on one coil may be answered if an analogous conundrum has been solved on another. The Table 1 compares nine independent, mathematically orthogonal, traditional, psychiatric and philosophic classifications. The astrological correlation between birth time and personality is consistent with the oxygen tension change at birth establishing a common base-line on every minion; their 2000 year 'Great Ages' and zodiac signs correspond to minion coil characteristics. Occult traditions support the minion concept.Minion memory storage is consistent with perfectpitchrecognition and Chinese tonal pronunciation. The musical stave's five lines and four spaces reflect the nine minion coils. Shakespeare's Portia in The merchant of Venice offering silver, lead and gold caskets and synaesthetes transposing sensesillustrate the meanings of colour. Gamblers are misled by confusing cardinal and ordinal numbers. The $\mathrm{H}$-bonds between amino acid $\omega$-amines and DNA phosphates oscillate like rows of dominoes collapsing, (Figure $4 \mathrm{~A}$ ), constituting the eighteen hands of biological clocks with time unit:

$$
\tau=3^{\star} 189^{\star} 7.37^{\star} 10^{-10} / 3{ }^{\star} 10^{8} \approx 1.39 * 10^{-15} \text { seconds }
$$

where the initial ' 3 ' reflects Dekatron ${ }^{\text {tx }}$ logic [8], ' 189 ' is the number of base pairs per coil, $7.37 \tilde{\AA}$ the $\beta$-sheet spacing and $3^{*} 10^{8} \mathrm{~m} / \mathrm{s}$ the velocity of light. The times associated with its eighteen tracks, $63^{\mathrm{N}} \tau, \mathrm{N}$ $=11,13$ and 18, predict day length, Sun-spot cycle period and the 'age of the universe' respectively. Time intervals outside the range $\tau$ to $63^{18}$ $\tau$ such as the mathematical zero and infinity, 0 and $\infty$ are meaningless. Substituting $\tau$ for Planck's constant explainsHeisenberg'suncertainty principle. The 63 units forming each coil correlate with 60 seconds/ minute and minutes/hour, its prime factors, 7, 3 and 9 correlate with using base-10 arithmetic and assigning 7 days/week.
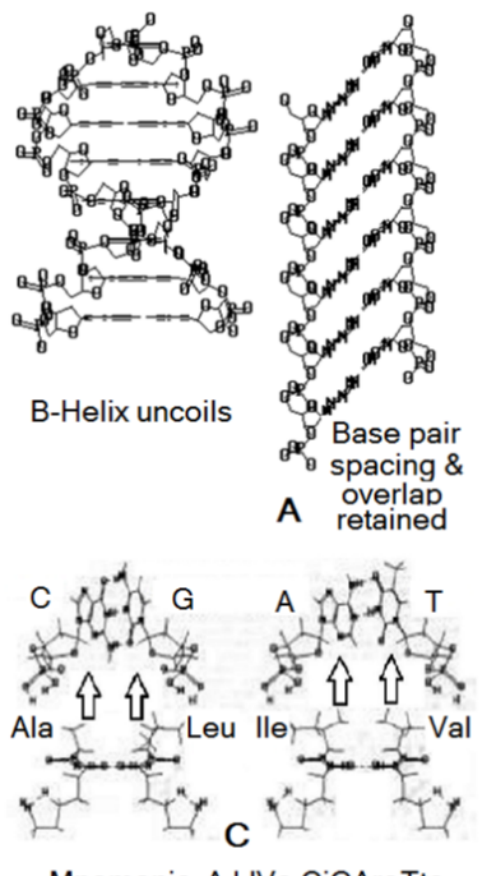

Mnemonic A LIVe CiGAreTte
B-Helix uncoils
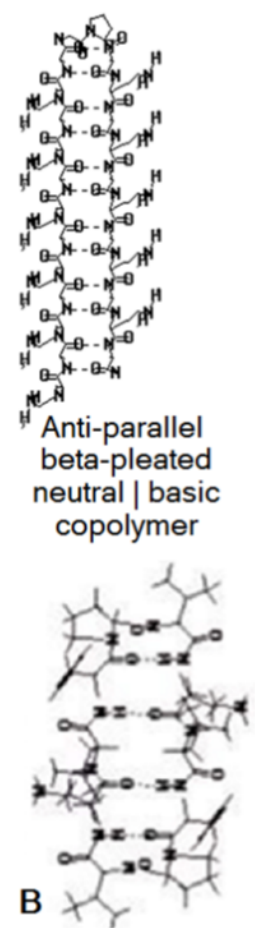

Gramicidin S
Figure 3: A. B-helix uncoils and binds to anti-parallel $\beta$-pleated sheet protein hairpin. B. Gramicidin S.C. Amino acids match base pairs.

\begin{tabular}{|c|c|c|c|c|c|}
\hline$\#$ & Quality & Period & Colour & Mass & Discipline \\
\hline-9 & unity & 8.7 fsec & red & $\mathrm{m}_{\mathrm{e}} / 7$ & quantum mechanics \\
\hline-8 & justice & $5.5 \mathrm{psec}$ & silver & $m_{p} / 7$ & physics \\
\hline-7 & stability & 350 psec & blue & $2 \mathrm{bp}$ & chemistry \\
\hline-6 & progress & 22 nsec & violet & $8.3 \mathrm{ag}$ & computer processing \\
\hline-5 & Love & $1.4 \mu \mathrm{sec}$ & bronze & $33 \mathrm{fg}$ & biochemistry \\
\hline-4 & Peace & $87 \mu \mathrm{sec}$ & yellow & $130 \mathrm{pg}$ & genetics \\
\hline-3 & beauty & $5.5 \mathrm{msec}$ & pied & $0.51 \mu \mathrm{g}$ & biology \\
\hline-2 & truth & $350 \mathrm{msec}$ & gold & $2 \mathrm{mg}$ & engineering \\
\hline-1 & goodness & $22 \mathrm{sec}$ & green & $8.1 \mathrm{~g}$ & psychology \\
\hline+1 & goodness & $23 \mathrm{~min}$ & green & $32 \mathrm{~kg}$ & psychiatry \\
\hline+2 & truth & 1 day & gold & $130 t$ & head hunting \\
\hline+3 & beauty & 9 weeks & pied & $0.5 \mathrm{Mt}$ & sociology \\
\hline+4 & peace & $11 \mathrm{yr}$ & yellow & $2000 \mathrm{Mt}$ & politics \\
\hline+5 & love & $685 \mathrm{yr}$ & bronze & $8 \mathrm{Gt}$ & history \\
\hline+6 & progress & $43,000 \mathrm{yr}$ & violet & $31 \mathrm{Pt}$ & archaeology \\
\hline+7 & stability & $2.7 \mathrm{Myr}$ & blue & 1.8 Moons & palaeontology \\
\hline+8 & Justice & 170 Myr & silver & 84 Earths & astronomy \\
\hline+9 & Unity & 11Byr & red & 1 Sun & cosmology \\
\hline
\end{tabular}

Where periods $=63^{\mathrm{N}} \mathrm{T}, \mathrm{T} \sim 1.4^{*} 10^{-15} \mathrm{sec}$ is the minion time unit. Colours feature in metaphors, adverts, national flags and political party logos. The ratio between masses $=63^{2}, m_{e}=$ electron mass, $m_{p}=$ proton mass, $b p=$ base pair, $a=10^{-18}, f=$ $10^{-15}, \mathrm{p}=10^{-12}, \mathrm{n}=10^{-9}, \mu=10^{-6}, \mathrm{~m}=10^{-3}, \mathrm{k}=10^{3}, \mathrm{M}=10^{6}, \mathrm{G}=10^{9}, \mathrm{~T}=10^{12}$ andP $=10^{15}$. Replacing $\mu=\sqrt{ } \mathrm{M}$ for mass $\mathrm{M}$ in Albert Einstein's $\mathrm{E}=\mathrm{Mc}^{2}$ yields the more symmetric $E=\mu^{2} c^{2}$.

Table 1: Associations with minion coils.

\section{Trace Element Nutrition}

Most carriers invoke trace element ions. Micronutrient deficient diets arise as civilizations evolve. The minion's nine coils control nine mutually independent biochemical systems. Each has associated 


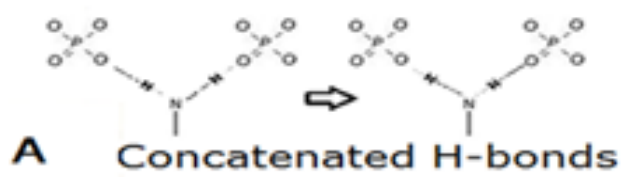

Figure 4A: H-bonds between amino acid $\omega$-amines and DNA phosphates oscillate.

tDNAs,substrates, carriers,glands,hormones, vitamins,nutrient requirements, chemistry and pathology. They facilitate diagnosis, prevention and treatment of most common maladies.

\section{Motility}

Vitamin A is either retinol or retinal, depending on $\mathrm{pH}$. Retinal's conjugated $(-\mathrm{C}-\mathrm{C}=\mathrm{C}-)_{\mathrm{n}}$ bonds conduct energy through membranes as solutions [9], converting the sulphur in glutathioneto sulphite, $\mathrm{SO}_{3}{ }^{3}$. Likewise vitamin $\mathrm{E}$, $\alpha$-tocopherol delivers energy converting the selenium, $\mathrm{Se}$ in oxytocin and vasopressin to selenite, $\mathrm{SeO}_{3}=\mathrm{SO}_{3}=$ and $\mathrm{SeO}_{3}=$ exchange $\mathrm{Mg}^{++}$and $\mathrm{Mn}^{++}$for $\mathrm{Ca}^{++}$respectively, (Figure $5 \mathrm{~A}$ ). $\mathrm{Mg}$ catalyzes hydrolysis of ATP, releasing ice light energy. Sarcomeres contract to form $1 / 2 \lambda$ resonant cavities. For sustained muscle contraction, exchanging creatine for creatinine phosphate replenishes ATP.

\section{Sensitivity}

Nerves serve as wave guides, enabling minions throughout the body to resonate, transmitting pleasure andpain. Catecholamines adrenalin, noradrenalin and dopamine exchange sodium ions, $\mathrm{Na}^{+}$for potassium, $\mathrm{K}^{+}$at synapses. $\mathrm{Na}^{+}$has the same shape and size as $\mathrm{H}_{2} \mathrm{O}$, forming large hydrates such as $\mathrm{Na}^{+} .28 \mathrm{H}_{2} \mathrm{O}$, making thecellsap viscous and slowing metabolism. $\mathrm{K}^{+}$binds less water, enablingfasterreactions. Four- and six-member catecholamine rings exchange $3 \mathrm{Na}^{+}$for $2 \mathrm{~K}^{+}$, explaining the 'fight or flight' reaction, (Figure 5B). Substituting codeine or morphine creates larger complexes, preventing pain by blocking the pump. Sensitivity increases when more pumps are enrolled to compensate, explaining drug addiction.

\section{Excretion}

Excretion of salt, $\mathrm{NaCl}$ and exhaling carbon dioxide, $\mathrm{CO}_{2}$ regulate ionic strength and acidity, $\mathrm{pH}$. Manganesechlorides: $\mathrm{MnCl}_{3}^{-}, \mathrm{MnCl}_{4}=$ and $\mathrm{MnCl}_{6}{ }^{4-}$ carry $\mathrm{NaCl}$, subject to aldosterone,angiotensin,rennin, histamine and aspirin. The 'chloride shift', catalyzed by $\mathrm{Zn}$-dependent carbonic anhydrase:

$$
\mathrm{CO}_{2}+\mathrm{H}_{2} \mathrm{O} \leftrightarrow \mathrm{HCO}_{3}^{-}+\mathrm{H}^{+}
$$

and red cells, erythrocytes exchanging $\mathrm{Cl}^{-}$for $\mathrm{HCO}_{3}{ }_{3}^{-}$control $\mathrm{pH}$.

\section{Respiration}

Erythrocyte haemoglobin transports $\mathrm{O}_{2}$, breathing exchanges it for $\mathrm{CO}_{2}$. The thyroids distribute iodine in thyroxin, $\mathrm{T}_{4}$. Protons at target tissues displace metallic iodine, $\mathrm{I}^{+}$, carrier for $\mathrm{O}_{2} \cdot \mathrm{H}_{2} \mathrm{O}$, (Figure $5 \mathrm{C}$ ). Littoral seaweeds use iodine to protect them from tidal changes in oxygen concentration, their purple and ochre colours match those of $\mathrm{I}^{+}$and $\mathrm{I}^{-}$. tDNAs accelerate protons causing nitrogen, $\mathrm{N}_{2}$, oxygen, $\mathrm{O}_{2}$ and nitric oxide, $\mathrm{NO}$ to bond with the amide group ofnicotinamide in NAD or NADP. This accounts for nitrogen fixation releasing hydrogen, photolysis of water oxygenating the atmosphere and how NO controls vasodilation. Hydrogen cyanide, HCN and carbon monoxide, $\mathrm{CO}$ toxicity blockthis tDNA. Iodine deficiency causes goitre. $\mathrm{I}^{-}$accumulating in the eyes causes exopthalmos.Mutant tDNAs disrupting nerve cell oxygenation explain bipolar disorder, mania and depression correspond to excess or deficient $\mathrm{O}_{2}$ supply to brain cells. Lithium, $\mathrm{Li}^{+}$diagonally related to $\mathrm{I}^{+}$in the periodic table, stabilizes the condition by substituting for $\mathrm{I}^{+}$.

\section{Growth}

The anterior pituitary gland packs copper, $\mathrm{Cu}$ into growth hormones, $\mathrm{Cu}^{++}$carries amino acids, c.f. Biuret test. tRNAs transfer amino acids through the endoplasmic reticulum membrane to ribosomes for protein synthesis. Failure causes growth defects: gigantism,dwarfism and acromegaly.Cuaccumulating inthe eyes causes Wilson's disease. $\mathrm{Cu}$ supplements and bracelets may relieve arthritis. Differentiation DNAs, dDNAs coordinate tDNAs, analogous to mRNAs selecting tRNAs. Stem cells have a full complement of tDNAs. At stages in tissue differentiation such as gastrulation and blastulation, tDNAs are starved of nutrients and overheat, causing reversal of dDNA binding. Reversed tDNA sequences encode 'hook' proteins, determining tissue morphology:

1. Eggs, sperm and immune system leukocytes have 1 hook

2. Spirogyra filaments have 2 hooks

3. Sponge sheets have 3 hooks

4. Bi-layered worms have 4 hooks

5. Liver and other organs use 5 hooks

6. 6hooks allow tumourand cancer growth controlled by leukocytes.

\section{Rigidity}

Fluorspar, $\mathrm{CaF}_{2}$ illustrates the high affinity of calcium, $\mathrm{Ca}^{++}$for
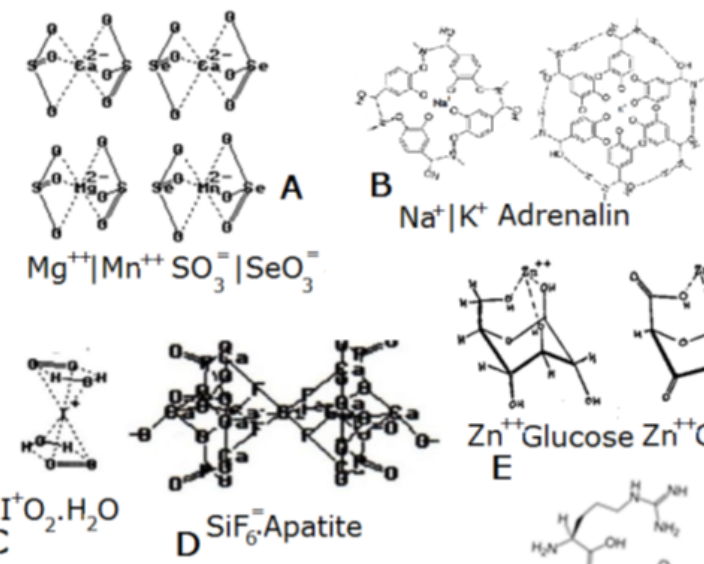

$\mathrm{a}^{+} \mid \mathrm{K}^{+}$Adrenalin

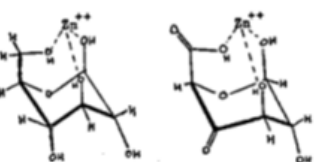

$\mathrm{Zn}^{++}$Glucose $\mathrm{Zn}^{++}$Gulonate

$\mathrm{E}$

$$
\mathrm{C}^{\mathrm{I}^{+} \mathrm{O}_{2} \cdot \mathrm{H}_{2} \mathrm{O} \quad \mathrm{D}^{\mathrm{SiF}_{6}^{-}} \text {.Apatite }}
$$

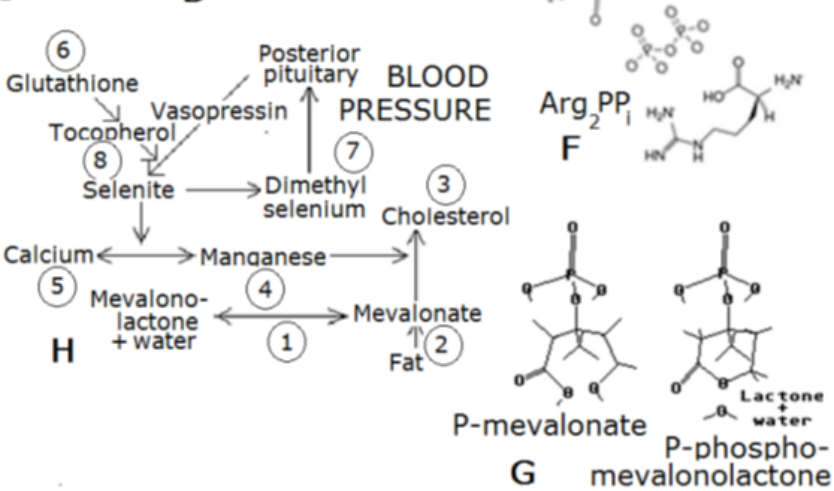

Figure 5: A. Motility, B. Sensitivity, C. Respiration, D. Rigidity, E. Assimilation, F. Reproduction, G. Osmoregulation, H. Blood pressure controls. 
fluoride, $\mathrm{F}^{-}$. The parathyroid and coevolved thyroid glands adjacent in the neck both incorporate halides to hormones. Continuous secretion of parathyroid hormone, PTH prevents high F- concentrations damaging these glands. Vitamin D stores ultraviolet sunlight with wavelength $\sim 265 \mathrm{~nm}$, creating $\mathrm{Si} \sim \mathrm{F}$ bonds for assembling silicon hexafluoride, $\mathrm{SiF}_{6}{ }^{=}$at low $\mathrm{pH}$ :

$$
\mathrm{SiO}_{2}+6 \mathrm{~F}^{-}+4 \mathrm{H}^{+}+\mathrm{UV} \text {-light } \rightarrow \mathrm{SiF}_{6}{ }^{=}+2 \mathrm{H}_{2} \mathrm{O} .
$$

$\mathrm{SiF}_{6}=$ carries calcium phosphate, apatite, maintaining bones and teeth, (Figure 5D). The low $\mathrm{pH}$ associated with kidney failure and menopause reduces phosphate availability, causing osteoporosis. For plant life, phosphate, $\mathrm{P}_{\mathrm{i}}$ is scarce. They employ the same substratecarrier complex to form their silica, $\mathrm{SiO}_{2}$ hard parts. Acid air pollution, $\mathrm{SO}_{x}$ and $\mathrm{NO}_{x}$ entering stomata causes leaf-fall. Liming the soil is ineffective, delaying action on controlling acid air pollution [10]. Acid air pollution and tobacco smoke lower the $\mathrm{pH}$ in the cavity behind the nose, promoting inappropriate $\mathrm{SiF}_{6}=$ synthesis. Breakdown of $\mathrm{SiF}_{6}=$ passing along the olfactory nerves tothebrain causes Alzheimer's disease.Fluoridedisrupts the H-bonds involved in protein folding, yielding the characteristic protein tangles. Mutant tRNAs incorporating the wrong amino acid to some proteins also cause tangled proteins in prion diseases. Mutant tRNAs embedded in these proteins render them infectious agents.Cod liver oil, UV lamps or sunlight prevent rickets due to infant vitamin D deficiency. Fluoridation of water supplies counters childhood tooth decay, hardening tooth enamel by replacing $\mathrm{OH}^{-}$with $\mathrm{F}^{-}$. Tea supplies adequate $\mathrm{F}^{-}$. Fluorinated anaesthetics promote fluoride excretion as aluminium hexafluoride, $\mathrm{AlF}_{6}{ }^{\otimes}$ four days later. Simultaneous brain clearance temporarily relieves dementia, suggesting approaches for its prevention and treatment.

\section{Assimilation}

Pavlov's dog anticipating food caused pancreatic insulin secretion. In man, the sight, smell or timeliness of food have the same effect. Zinc, $\mathrm{Zn}^{++}$primes tDNA pumps to carry $\beta_{\mathrm{D}}$ glucose, (Figure 5E). Glucose transport, maintaining steady blood glucose concentrations, mediates carbohydrate metabolism. Plants maintain glucose levels in xylem and phloem. Converting glucose to glycogen or fat in liver or starch in leaves also mediates glucose homeostasis. $\mathrm{Zn}^{++}$binds to the 'triangle of sweetness'[11] found in insulin and glucagon. Insulin synthesised in the pancreatic $\beta$-cells distributes $\mathrm{Zn}$ and glucagon synthesised in pancreatic $\alpha$-cells recycles it. Banting and Best discovered insulin and Dorothy Hodgkin determined its structure [12]. Vitamin C derivative ${ }_{\mathrm{L}}$ gulonatetakes $\mathrm{Zn}$ where insulin can't reach. Vitamin $\mathrm{C}$ deficiency reduces $\mathrm{Zn}$-mediated hydroxyproline incorporation for collagen synthesis causing scurvy in ancient mariners until limes supplemented their food.Zinc sulphide, $\mathrm{ZnS}$ in Calamine ${ }^{\mathrm{Tn}}$ lotion treats skin complaints. Glucosetransport defects cause diabetes and its sideeffects: $\mathrm{Zn}$ accumulating in the vitreous humour damages the retina, causing blindness. Kidney damage and foot problems frequently arise. Assessing $\mathrm{Zn}$ intake or implanting a glucose concentration monitor might improve management. $\mathrm{Zn}$ regulates our appetites for food and sex. Zn-rich appetizers such as oysters or caviar encourage snacking, eating disorders anorexia and bulimia respond to $\mathrm{Zn}$ supplements. Aphrodisiacs containing $\mathrm{Zn}$ increase libido. $\mathrm{Cu}$ coil contraceptives prevent sperm getting enough $\mathrm{Zn}$ for glucose assimilation to reach their targets.Neonatal jaundice arises when bilirubin released from the transition between foetal and adult haemoglobin isn't conjugated with glucose for excretion. Seizures result if bilirubin enters the bran, the usual treatment is exposure to blue light, $\mathrm{Zn}$ in colostrum from breast feeding the natural remedy. Sucking a midwife's Zn-basedpewter spoon was effective, failing when blue-blooded families substituted a silver spoon. Rhinoviruses causing colds and flu enter nasal cells via tDNAs,
Zn supplements block virus uptake. The detoxification of alcohol and barbiturates diverts $\mathrm{Zn}$, cofactor for alcohol dehydrogenase, to the liver. This prevents sufficient $\mathrm{Zn}$ for glucose transport reaching the brain, causing inebriety. Combining barbiturates with alcohol can be lethal. Designing treatments for alcoholism need focus on Zn.Victorians called beryllium, $\mathrm{Be}^{++}$'glucinium' for its sweet taste, using it as a poison. Romans died from using lead acetate as a sweetener. Exchanging indium, In, diagonally related to $\mathrm{Zn}$ in the periodic table, for divalent trace metals may enable their uptake by endocrine glands for incorporation to hormones. Indium has been promoted for treating obesity. $\mathrm{Be}^{++}, \mathrm{Pb}^{++}$and $\mathrm{In}^{++}$mimic $\mathrm{Zn}^{++}$.

\section{Reproduction}

Thepineal glanddistributes silver, $\mathrm{Ag}^{+}$in six-member serotonin ringsresembling those catecholamines form around $\mathrm{K}^{+}$. Retinal transfers energy for converting $\mathrm{P}_{\mathrm{i}}$ to pyrophosphate, $\mathrm{PP}_{\mathrm{i}}$ from pink $\mathrm{Ag}$ porphyrin as solitons, see Motility. The $\mathrm{Arg}_{2}$. $\mathrm{PP}_{\mathrm{i}}$ complex provides the atomic ingredients for copying DNA at cell division [13]; anti-cancer agents mimic it, (Figure 5F). Before the advent of antibiotics, Ag was often used for tissue repair and sleep regulation. Deficiency may allow cancers to develop. Phosphate, $\mathrm{P}_{\mathrm{i}}$ use is independently handled for energy management, DNA synthesis and skeletal maintenance.

\section{Osmoregulation}

Membrane potential prevents water diffusing through, accepting this fact is prerequisite to preventing most Western deaths. Ponder absorbing bath water through leaky skin. The residueofsaturatedfat breakdown, phospho-mevalonate, namedafter the herb Valerian, aka 'Allheal', reversibly forms a lactone ring, (Figure 5G). Exchanging phospho-mevalonate for its lactone transports water.The posterior pituitary gland packs selenium, Se into oxytocin and vasopressin. Vitamin E, a-tocopherol transmits energy for oxidising Se to $\mathrm{SeO}_{3}{ }^{=}$through the membrane as solitons, see Motility. $\mathrm{SeO}_{3}{ }^{=}$exchanges $\mathrm{Ca}^{++}$for $\mathrm{Mn}^{++}$, cofactor for cholesterol synthesis from mevalonate. This by-product of osmoregulation is feedstock for steroid hormones. Se deficiency arises from water purification [14], displacement by such sulphurous fertilizers as superphosphate [15], cropping low-Se soils, using high temperatures when preparing and preserving food and poor nutrition. It causes hypertension of pregnancy, heart attacks and cancers of tissues specializing in pumping water: breast, bowel, cervix and prostate. It may contribute to Ebola [16]. Supporting evidence abounds, the consistent correlation between breast cancer distribution and surface geology [17] is compelling. Hard water from limestone in London and such igneous deposits as those in Snowdonia contain most Se, presumably recycled from early life. Se-rich diets account for the longevity of European royal families. Sea floor Mn nodules may reflect Se metabolism. Animal husbandry [18] provides the best evidence for Se dependency. Se supplementation protects cattle from hypertension during pregnancy, sheep from white muscle disease and pigs from heart failure en route to market. Limes for scurvy, iodine for goitre, cod liver oil for rickets and fluoridation for dental caries are precedents for intervention.

Blood pressure disorders, (Figure $5 \mathrm{H}$ ), can be corrected by attention to:

\section{The tDNA exchanging phospho-mevalonate for its lactone.}

\section{Saturated fat consumption.}

3. Lipids transporting cholesterol.

4. Manganese, cofactor for cholesterol synthesis.

5. Exercise and using aspirin to regulate calcium levels. 
Citation: Deans MT (2015) A Ferroelectric Transition in Proton Ordered Ice Crystallised in Liquid Nitrogen released Laser Light, Explaining the Origin of Life with many Consequences. Med chem 5: 211-216. doi:10.4172/2161-0444.1000266

6. Glutathione production by the liver.

7. Methyl mercury, $\mathrm{HgMe}^{+}$preventing pituitary dimethl-Se, $\mathrm{Me}_{2} \mathrm{Se}^{+}$ uptake.

8. Selenium and vitamin E deficiency.

\section{References}

1. http://www1.Isbu.ac.uk/water/water_structure_science

2. Zhao HX, Kong XJ, Li H, Jin YC, Long LS, et al. (2011) Transition from onedimensional water to ferroelectric ice within a supramolecular architecture. Proc Natl Acad Sci USA 108: 3481-3486.

3. ShachtmanT (2008) Physicists in Massachusetts come to grips with the lowest possible temperature: absolute zero, Smithsonian Magazine.

4. [No authors listed] (2010) Workshop OQOL'09: Open Questions on the Origins of Life 2009, Palacio Miramar, San Sebastian-Donostia, Spain, May 20-23, 2009. Abstracts. Orig Life Evol Biosph 40: 347-497.

5. Sussman JL, Kim S (1976) Three-dimensional structure of a transfer rna in two crystal forms. Science 192: 853-858.

6. Huxley AF (1957) Muscle structure and theories of contraction. Prog Biophys Biophys Chem 7: 255-318.

7. Mitchell $P$ (1961) Coupling of phosphorylation to electron and hydrogen transfer by a chemi-osmotic type of mechanism. Nature 191: 144-148.
8. MacDougall MA (1965) Using the cold-cathode tube: part, Electronics p78.

9. Sinkala Z (2006) Soliton/exciton transport in proteins. J Theor Biol 241: 919927.

10. Likens GE, Wright RF, Galloway JN, Butler TJ (1979) Acid rain, Scientific American, 241: 43-51

11. Hough L,Emsley J (1986) The shape of sweeteners to come, New Scientist 1513

12. Blundell TL, Cutfield JF, Cutfield SM, Dodson EJ, Dodson GG, et al. (1971) Atomic positions in rhombohedral 2-zinc insulin crystals. Nature 231: 506-511.

13. Ruderman NB, Saha AK, Vavvas D, Witters LA (1999) Malonyl-CoA, fue sensing, and insulin resistance. Am J Physiol 276: E1-E18.

14. (2004) WHO, Health risks from drinking demineralised water, Geneva.

15. Freeman $R$ (2014) Four types of dangerous fertilizers that are used for farming Health care \& services guide

16. Sakurai Y, Kolokoltsov AA, Chen CC, Tidwell MW, Bauta WE, et al. (2015) Ebola virus. Two-pore channels control Ebola virus host cell entry and are drug targets for disease treatment. Science 347: 995-998.

17. (2010) Cancer research, GIS \& Science, USDS, Surface geology USA

18. MacPherson A, Barclay MNI, Scott R, Yates RWS (1997) Loss of Canadian wheat imports lowers selenium intake and status of the Scottish population In: Trace Elements in Man and Animals-Proceedings of $9^{\text {th }}$ International Symposium on Trace Elements in Man and Animals. 